\title{
Long non-coding RNA profiling of pediatric Medulloblastoma
}

\author{
Varun Kesherwani ${ }^{1}$, Mamta Shukla², Don W. Coulter ${ }^{3}$, J. Graham Sharp², Shantaram S. Joshi ${ }^{2}$ and \\ Nagendra K. Chaturvedi ${ }^{3,4^{*}}$
}

\begin{abstract}
Background: Medulloblastoma (MB) is one of the most common malignant cancers in children. $\mathrm{MB}$ is primarily classified into four subgroups based on molecular and clinical characteristics as (1) WNT (2) Sonic-hedgehog (SHH) (3) Group 3 (4) Group 4. Molecular characteristics used for MB classification are based on genomic and mRNAs profiles. MB subgroups share genomic and mRNA profiles and require multiple molecular markers for differentiation from each other. Long non-coding RNAs (IncRNAs) are more than 200 nucleotide long RNAs and primarily involve in gene regulation at epigenetic and post-transcriptional levels. LncRNAs have been recognized as diagnostic and prognostic markers in several cancers. However, the IncRNA expression profile of MB is unknown.
\end{abstract}

Methods: We used the publicly available gene expression datasets for the profiling of IncRNA expression across MB subgroups. Functional analysis of differentially expressed IncRNAs was accomplished by Ingenuity pathway analysis (IPA).

Results: In the current study, we have identified and validated the IncRNA expression profile across pediatric MB subgroups and associated molecular pathways. We have also identified the prognostic significance of IncRNAs and unique IncRNAs associated with each MB subgroup.

Conclusions: Identified IncRNAs can be used as single biomarkers for molecular identification of MB subgroups that warrant further investigation and functional validation.

Keywords: Long non-coding RNA, Pediatric Medulloblastoma, Cancer biomarkers, Gene expression and pathways, Therapeutic targets

\section{Background}

Medulloblastoma (MB), the most common pediatric brain tumor, constitutes nearly $20 \%$ of newly diagnosed brain tumors in children $[1,2]$. Treatment of $M B$ involves radiation therapy, chemotherapy and surgical resection. These strategies have improved the survival by $70-80 \%$ but also lead to serious morbidities [3, 4]. MB are classified into four major molecular subgroups as WNT, Sonic hedgehog (SHH), Group 3 and Group 4.

\footnotetext{
* Correspondence: nchaturvedi@unmc.edu

${ }^{3}$ Department of Pediatrics, Hematology and Oncology Division, University of Nebraska Medical Center, Omaha, NE 986395, USA

${ }^{4}$ Nebraska Medical Center, Omaha, NE, USA

Full list of author information is available at the end of the article
}

The WNT subgroup is least common among all 4 subgroups and present in only $10 \%$ of cases. Genetic changes in genes: CTNNB1, DDX3X, SMARCA4 and $D K K 1$ are frequently observed in the WNT subgroup. WNT has the best prognosis among all types of MB. $\mathrm{SHH}$ is second most common subgroup with abnormalities in SHH signaling pathway and accounts for 30\% of total MB cases. Genetic anomalies in genes: $M Y C N$, GLI1, PTCH1, SUFU, MLL2, SMO, TP53, BCOR1, $G A B 1, G A B R G 1$ and $L D B 1$ are frequently seen in the SHH subgroup. The SHH subgroup has an intermediate prognosis among MB subgroups. Group 3 is the third most common subgroup with $25 \%$ of the total MB cases.

(c) The Author(s). 2020 Open Access This article is licensed under a Creative Commons Attribution 4.0 International License, which permits use, sharing, adaptation, distribution and reproduction in any medium or format, as long as you give appropriate credit to the original author(s) and the source, provide a link to the Creative Commons licence, and indicate if changes were made. The images or other third party material in this article are included in the article's Creative Commons licence, unless indicated otherwise in a credit line to the material. If material is not included in the article's Creative Commons licence and your intended use is not permitted by statutory regulation or exceeds the permitted use, you will need to obtain permission directly from the copyright holder. To view a copy of this licence, visit http://creativecommons.org/licenses/by/4.0/ The Creative Commons Public Domain Dedication waiver (http://creativecommons.org/publicdomain/zero/1.0/) applies to the data made available in this article, unless otherwise stated in a credit line to the data. 
Table 1 Top 10 up-regulated IncRNAs in WNT subgroup of MB

\begin{tabular}{llll}
\hline Gene Symbol & Fold Change & P-val & FDR P-val \\
\hline EMX2OS & 38.18 & $9.01 \mathrm{E}-14$ & $4.92 \mathrm{E}-10$ \\
OTX2-AS1 & 37.84 & $1.14 \mathrm{E}-09$ & $3.93 \mathrm{E}-07$ \\
PGM5-AS1 & 30.26 & $9.54 \mathrm{E}-09$ & $1.63 \mathrm{E}-06$ \\
DSCR8 & 24.56 & 0.0001 & 0.0013 \\
LOXL1-AS1 & 21.06 & $1.03 \mathrm{E}-08$ & $1.73 \mathrm{E}-06$ \\
HAND2-AS1 & 18.51 & $9.37 \mathrm{E}-07$ & $3.59 \mathrm{E}-05$ \\
TMEM51-AS1 & 16.9 & $3.88 \mathrm{E}-09$ & $8.82 \mathrm{E}-07$ \\
RMST & 13.92 & $1.14 \mathrm{E}-07$ & $8.49 \mathrm{E}-06$ \\
LINC01305 & 11.11 & 0.0001 & 0.001 \\
PART1 & 10.94 & $1.89 \mathrm{E}-05$ & 0.0003
\end{tabular}

Group 3 is mainly MYC-driven and genetic aberrations are seen in genes: MYC, PVT1, OTX2, MLL2, $S M A R C A 4$, and CHD7 in this subgroup. The prognosis of the Group 3 is very poor and 5 year overall survival is less than $50 \%$. Group 4 is the most common subgroup of $\mathrm{MB}$ and accounts for $35 \%$ of total cases. The prognosis of the Group 4 is intermediate and genetic aberrations are commonly present in genes: OTX2, $D D X 31$, CHD7, NCAIP, MYCN, CDK6, GFI1/GFI1B, MLL2, KDM6A, MLL3, and ZMYM3 [5-9]. Molecular markers used for WNT identification are CTNNB1 (nuclear), FLIA, YAP1 and DKK1; for SHH are SFRP1, GLI1, FLIA, YAP1 and GAB1; for Group 3, NPR3; and for Group 4, KCNA1. Identification of new molecular markers for drug targeting, diagnosis and prognosis are important due to need for improved molecular profiling of $\mathrm{MB}$ [10].

Long non-coding RNAs (LncRNAs) are RNAs of more than $200 \mathrm{bp}$ in length and can be transcribed from an intergenic region, genic regions or super enhancer regions in the genome. LncRNAs can modulate chromatin structure, gene regulation via interactions with epigenetic modifiers and transcriptional co-factors, and also have post-translation effects via affecting the stability of mRNA or proteins [11, 12]. Deregulated lncRNA expression is associated with many cancers [13]. LncRNA signatures have been used to classify different types of cancer as biomarkers for diagnosis, prognosis and therapy [14-18]. LncRNAs are secreted in serum, plasma, and CSF in a stable form protected from endogenous RNAase and can be used for noninvasive analysis from patient samples [19, 20]. The role of lncRNA in brain development is well studied [21-26]. However, there is not much known about role of lncRNAs in MB. LncRNA LOXL1-AS1 promotes the proliferation and metastasis of $\mathrm{MB}$ by activating the PI3K-AKT pathway [27]. LncRNA CCAT1 promotes cell proliferation and metastasis in human

Table 2 Top 10 down-regulated IncRNAs in WNT subgroup of MB

\begin{tabular}{llll}
\hline Gene Symbol & Fold Change & $P$-val & FDR P-val \\
\hline LINC00461 & -62.39 & $1.16 \mathrm{E}-06$ & $4.17 \mathrm{E}-05$ \\
MEG3 & -58.9 & $9.41 \mathrm{E}-07$ & $3.60 \mathrm{E}-05$ \\
LINC00844 & -24.94 & 0.0003 & 0.0024 \\
LINC00643 & -13.3 & $6.95 \mathrm{E}-06$ & 0.0001 \\
SOX2-OT & -12.13 & 0.0003 & 0.0024 \\
PEG3-AS1 & -10.02 & $3.49 \mathrm{E}-07$ & $1.84 \mathrm{E}-05$ \\
TUNAR & -7.72 & $2.04 \mathrm{E}-12$ & $5.87 \mathrm{E}-09$ \\
MALAT1 & -7.39 & $1.65 \mathrm{E}-07$ & $1.10 \mathrm{E}-05$ \\
LINC01105 & -7.39 & $3.77 \mathrm{E}-05$ & 0.0005 \\
LINC01351 & -6.48 & $2.24 \mathrm{E}-05$ & 0.0003 \\
\hline
\end{tabular}




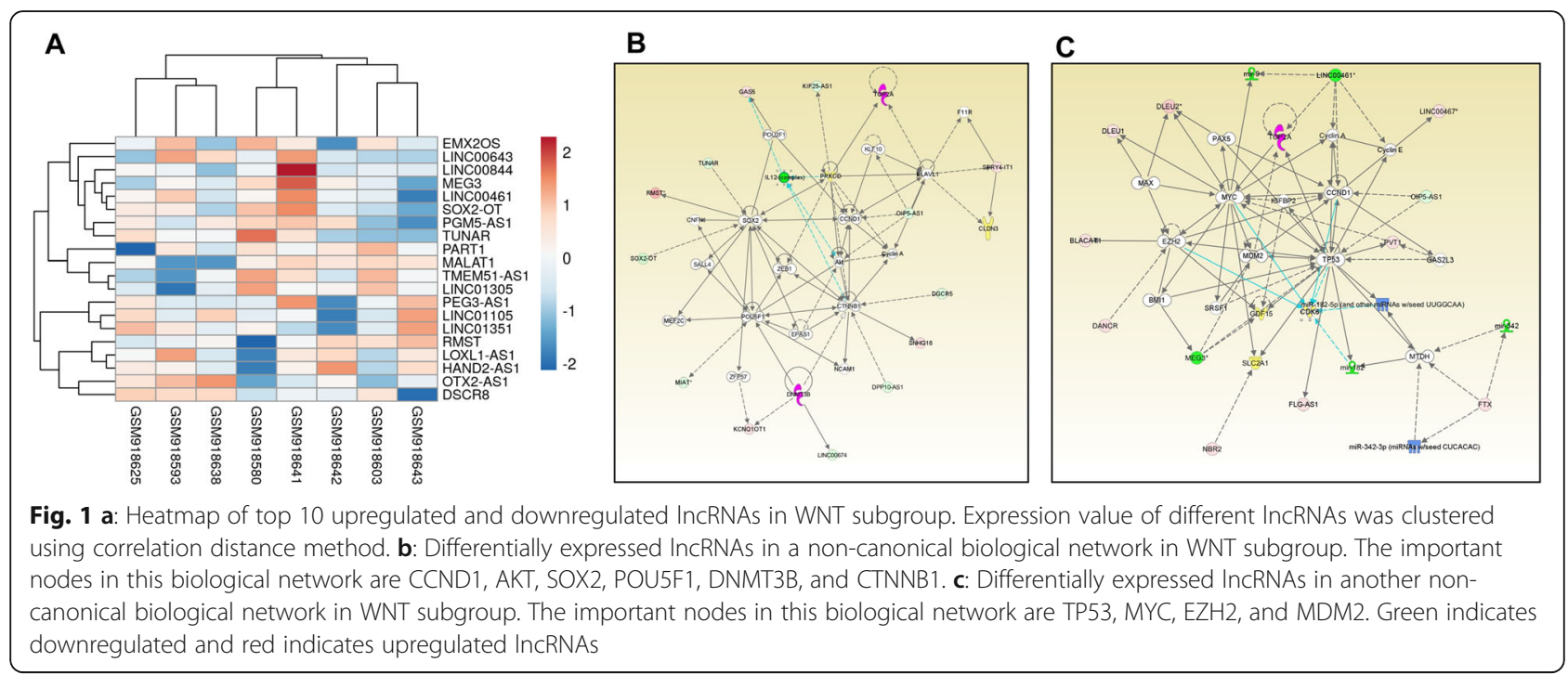

MB by regulating the MAPK pathway [28]. Silencing of ANRIL in MB cell lines significantly lowered cell viability and migration. ANRIL promoted the apoptosis of MB cell lines through miR-323-mediated regulation of BRI3, which activates p38 MAPK, ERK, and AKT as well as the WNT signaling pathway [29]. LINC-NeD125 expression is upregulated in Group 4 $\mathrm{MB}$ and after interacting to miRNA-induced silencing complex(MISC), it directly binds to miR-19a-3p, miR19b-3p and miR-106a-5p. Functionally, LINC-NeD125 acts by sequestering the three miRNAs, which leads to the de-repression of major driver genes (CDK6, $M Y C N, S N C A I P$, and KDM6A) of Group $4 \mathrm{MB}$ [30]. LncRNA CRNDE expression is elevated in $M B$ and knockdown of CRNDE significantly reduced cell proliferation and inhibited colony formation in $\mathrm{MB}$ cell lines, Daoy and D341 [31].
In the current study, we have identified the lncRNAs expression profile of pediatric MB subgroups and associated molecular pathways. We have also identified the unique lncRNAs associated with each subgroup.

\section{Methods}

We searched the Gene Expression Omnibus (GEO) database for $\mathrm{MB}$ related microarray datasets and found two relevant studies, GSE37418 [for pediatric MB subgroups expression data] and GSM1094863, GSM1094864, GSM1094865, GSM1094866, GSM1094867 [for pediatric primary cerebellum expression data from GSE44971] for our analyses. We further used large GSE124814 datasets for the validation of lncRNAs expression profiles of $\mathrm{MB}$ subgroups obtained from our original analyses. We selected the age $<18$ years as an inclusion criteria for selecting pediatric $\mathrm{MB}$ samples. We selected the datasets which

Table 3 Top 10 upstream regulators involved in DE IncRNAs in WNT subgroup

\begin{tabular}{llll}
\hline Upstream Regulator & Molecule Type & -val of overlap & Target molecules in dataset \\
\hline MAX & transcription regulator & $5.53 \mathrm{E}-03$ & DLEU1,DLEU2 \\
miR-150-5p (and other miRNAs w/seed CUCCCAA) & mature microRNA & $5.54 \mathrm{E}-03$ & MIAT \\
miR-133a-3p (and other miRNAs w/seed UUGGUCC) & mature microRNA & $7.38 \mathrm{E}-03$ & MALAT1 \\
mir-133 & microRNA & $9.22 \mathrm{E}-03$ & MALAT1 \\
FOLR1 & transporter & $1.31 \mathrm{E}-02$ & GAS5,PVT1 \\
E2f & group & $1.37 \mathrm{E}-02$ & DLEU1,DLEU2 \\
ATF5 & transcription regulator & $1.47 \mathrm{E}-02$ & GAS5 \\
NCAM1 & other & $1.84 \mathrm{E}-02$ & MALAT1 \\
mir-150 & microRNA & $2.56 \mathrm{E}-02$ & MIAT \\
GAS2L3 & other & $2.92 \mathrm{E}-02$ & PVT1
\end{tabular}


Table 4 Top 10 disease and function identified by IPA from DE IncRNAs in WNT subgroup

\begin{tabular}{|c|c|c|c|}
\hline Categories & Diseases or Functions Annotation & $P$-val & Activation z-score \\
\hline $\begin{array}{l}\text { Cellular Development, Cellular Growth and Proliferation, Nervous } \\
\text { System Development and Function }\end{array}$ & Neurogenesis of nervous tissue cell lines & $3.38 \mathrm{E}-06$ & \\
\hline Cellular Movement & Cell movement of tumor cell lines & $1.12 \mathrm{E}-05$ & 1.324 \\
\hline Cellular Movement & Migration of tumor cell lines & $1.14 \mathrm{E}-05$ & 1.498 \\
\hline Cellular Movement & Invasion of tumor cell lines & $1.55 \mathrm{E}-04$ & 1.083 \\
\hline Cell Cycle & Arrest in G0 phase of tumor cell lines & 3.83E-04 & \\
\hline Cancer, Organismal Injury and Abnormalities & Metastasis of tumor cell lines & 4.26E-04 & -0.277 \\
\hline Cell Death and Survival & Cell death of eye cell lines & 5.07E-04 & \\
\hline Cellular Movement & Migration of cells & 6.27E-04 & 0.573 \\
\hline Cellular Movement & Cell movement & $6.75 \mathrm{E}-04$ & 0.453 \\
\hline Cellular Movement & Migration of hepatoma cell lines & 1.34E-03 & \\
\hline
\end{tabular}

used the Affymetrix U133 Plus2 array for probe level RNA expression studies. For data analyses, we first did background correction, normalization (RMA), quality control checks, intensity and batch effect corrections of each dataset. Following that, we did probe level differential analyses of datasets using the limma package (ANOVA with eBayes) with criteria of $p<0.001$ and fold change greater than two folds. We then annotated the probe sets with the Affymetrix U133 Plus2 library and filtered out lncRNA genes. The lncRNA gene database used is verified and approved by HGNC. Functional analysis of differentially expressed lncRNAs was done by Ingenuity pathway analysis (IPA) software from BioRad, Inc. We used default parameters and checked all the node types, all species (except uncharted), and all tissue types for core analysis in IPA.

\section{Results}

Differentially expressed IncRNAs in the WNT subgroup and their functional roles

Comparative analyses of WNT $\mathrm{MB}(N=8)$ and normal cerebellum tissue $(N=5)$ datasets with $p<0.05$ and fold

Table 5 Top 10 up-regulated IncRNAs in SHH subgroup of MB

\begin{tabular}{llll}
\hline Gene Symbol & Fold Change & $P$-val & FDR $P$-val \\
\hline NEAT1 & 23.48 & 0.0003 & 0.0022 \\
DLEU2 & 13.24 & $5.79 \mathrm{E}-11$ & $2.41 \mathrm{E}-08$ \\
PRR34-AS1 & 8.07 & $1.58 \mathrm{E}-07$ & $8.49 \mathrm{E}-06$ \\
LINC01355 & 8.05 & $2.93 \mathrm{E}-09$ & $5.15 \mathrm{E}-07$ \\
MIRLET7BHG & 7.49 & $1.79 \mathrm{E}-07$ & $9.34 \mathrm{E}-06$ \\
CKMT2-AS1 & 6.23 & $1.86 \mathrm{E}-09$ & $3.59 \mathrm{E}-07$ \\
SLC16A1-AS1 & 5.65 & $8.13 \mathrm{E}-08$ & $5.36 \mathrm{E}-06$ \\
TPT1-AS1 & 5.28 & $4.44 \mathrm{E}-08$ & $3.50 \mathrm{E}-06$ \\
LINC01000 & 4.96 & $1.10 \mathrm{E}-08$ & $1.32 \mathrm{E}-06$ \\
ANP32A-IT1 & 4.94 & $9.36 \mathrm{E}-07$ & $3.07 \mathrm{E}-05$ \\
\hline
\end{tabular}

changes $>2$ provided 199 differentially expressed lncRNAs with approved status. Tables 1 and 2 show the fold change in the top 10 upregulated and downregulated lncRNAs. Heatmap of top 10 upregulated and downregulated IncRNAs is shown in Fig. 1a. The complete list of lncRNAs can be seen in Additional file 1. We found $73 \%$ overlap with lncRNAs in validation datasets [WNT $N=31$, Control =5] (Additional file 2). We found all the top 10 upregulated and downregulated lncRNAs present in validation datasets. We mostly see non-overlap in lncRNAs at lower expression values.

We did functional analysis of differentially expressed (DE) IncRNAs of the WNT subgroup using IPA. We identified different functional parameters involved in this subgroup. MAX (a MYC interacting partner), miR-150, miR-133a, FOLR1, E2F NCAM1, GAS2L3 and ATF5 are the most significantly associated upstream regulators, while cancer, neurogenesis, metastasis and cellular development are the most important biological functions

Table 6 Top 10 down-regulated IncRNAs in SHH subgroup of $\mathrm{MB}$

\begin{tabular}{llll}
\hline Gene Symbol & Fold Change & $P$-val & FDR P-val \\
\hline LINC00844 & -33.36 & $1.08 \mathrm{E}-08$ & $1.32 \mathrm{E}-06$ \\
MIR124-2HG & -28.13 & 0.0005 & 0.0032 \\
SOX2-OT & -13.83 & $2.39 \mathrm{E}-07$ & $1.15 \mathrm{E}-05$ \\
PEG3-AS1 & -12.94 & $5.12 \mathrm{E}-08$ & $3.88 \mathrm{E}-06$ \\
LINC00643 & -11.76 & $3.97 \mathrm{E}-06$ & $8.83 \mathrm{E}-05$ \\
HCG11 & -11.26 & 0.0012 & 0.0065 \\
RMST & -9.43 & 0.0036 & 0.0155 \\
CCEPR & -8.93 & $1.49 \mathrm{E}-06$ & $4.27 \mathrm{E}-05$ \\
MEG3 & -8.53 & 0.0002 & 0.0018 \\
MALAT1 & -8.25 & $2.82 \mathrm{E}-06$ & $6.86 \mathrm{E}-05$ \\
\hline
\end{tabular}




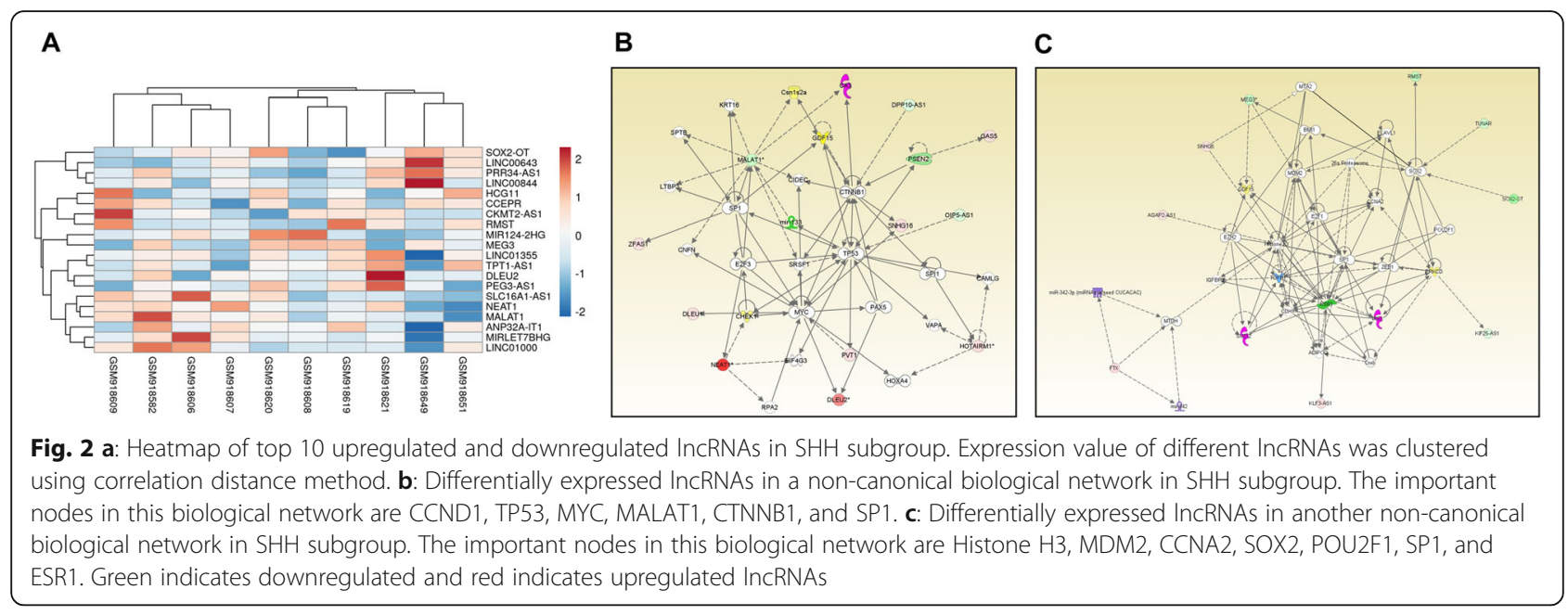

affected in this subgroup (Tables 3 and 4). Heatmap of 5 upstream regulators is shown in supplementary Fig. 1 (Additional file 3). The two most important noncanonical networks enriched with DE lncRNAs are shown in Fig. $1 \mathrm{~b}$ and $\mathrm{c}$. In networks 1; CCND1, AKT, SOX2, POU5F1, DNMT3B, and CTNNB1, in network 2; TP53, MYC, EZH2, and MDM2 are the central regulators linked with DE lncRNAs.

\section{Differentially expressed IncRNAs in the SHH subgroup and their functional roles}

Comparative analyses of the SHH subgroup $(N=10)$ and normal cerebellum tissue $(N=5)$ datasets with $p<0.05$ and fold change $>2$ provided 145 differentially expressed lncRNAs with approved status. Tables 5 and 6 show the fold change in the top 10 upregulated and downregulated IncRNAs. Heatmap of top 10 upregulated and downregulated lncRNAs is shown in Fig. 2a. The complete list of lncRNAs can be seen in Additional file 1. We found $50 \%$ overlap with lncRNAs in validation datasets [SHH $N=65$, Control=5] (Additional file 2). We found all the top 10, upregulated and downregulated lncRNAs, present in validation datasets except DLEU2 and PRR34-AS1.

Functional analysis of DE lncRNAs of SHH MB subgroup using IPA predicts, MAX (a MYC interacting partner), miR-133a, FOLR1, E2F, ATF5, AM1, E2F3, GAS2L3 and ACSL5 as most significantly associated upstream regulators, while cancer, neurogenesis, cell proliferation, metastasis and cellular development are the most important biological functions affected in this subgroup (Tables 7 and 8). Heatmap of 5 upstream regulators is shown in supplementary Fig. 1 (Additional file 3). The two most important non-canonical networks enriched with DE lncRNAs are shown in Fig. $2 b$ and c. In network 1; CCND1, TP53, MYC, MALAT1,

Table 7 Top upstream regulators involved in DE IncRNAs in SHH subgroup

\begin{tabular}{llll}
\hline Upstream Regulator & Molecule Type & P-val of overlap & Target molecules in dataset \\
\hline MAX & transcription regulator & $2.74 \mathrm{E}-03$ & DLEU1,DLEU2 \\
miR-133a-3p (and other miRNAs w/seed UUGGUCC) & mature microRNA & $5.17 \mathrm{E}-03$ & MALAT1 \\
mir-133 & microRNA & $6.46 \mathrm{E}-03$ & MALAT1 \\
FOLR1 & transporter & $6.58 \mathrm{E}-03$ & GAS5,PVT1 \\
E2f & group & $6.85 \mathrm{E}-03$ & DLEU1,DLEU2 \\
ATF5 & transcription regulator & $1.03 \mathrm{E}-02$ & GAS5 \\
NCAM1 & other & $1.29 \mathrm{E}-02$ & MALAT1 \\
E2F3 & transcription regulator & $1.49 \mathrm{E}-02$ & MALAT1,NEAT1 \\
GAS2L3 & other & $2.05 \mathrm{E}-02$ & PVT1 \\
ACSL5 & enzyme & $2.18 \mathrm{E}-02$ & ST7-AS1
\end{tabular}


Table 8 Top 10 disease and function identified by IPA from DE IncRNAs in SHH subgroup

\begin{tabular}{|c|c|c|c|}
\hline Categories & Diseases or Functions Annotation & $P$-val & Activation z-score \\
\hline $\begin{array}{l}\text { Cellular Development, Cellular Growth and Proliferation, } \\
\text { Nervous System Development and Function }\end{array}$ & Neurogenesis of nervous tissue cell lines & 1.79E-06 & \\
\hline Cellular Development, Cellular Growth and Proliferation & Proliferation of kidney cancer cell lines & $3.01 \mathrm{E}-06$ & -0.095 \\
\hline Cellular Development, Cellular Growth and Proliferation & Cell proliferation of tumor cell lines & 3.90E-04 & 0.933 \\
\hline Cellular Movement & Migration of carcinoma cell lines & $5.25 \mathrm{E}-04$ & 0.762 \\
\hline Cellular Movement & Migration of kidney cancer cell lines & $6.63 \mathrm{E}-04$ & \\
\hline Cellular Movement & Cell movement of tumor cell lines & $6.65 \mathrm{E}-04$ & 0.751 \\
\hline Cellular Movement & Migration of tumor cell lines & $1.14 \mathrm{E}-03$ & 1.033 \\
\hline Cellular Development, Cellular Growth and Proliferation & Cell proliferation of carcinoma cell lines & $1.30 \mathrm{E}-03$ & 0.277 \\
\hline $\begin{array}{l}\text { Cellular Development, Connective Tissue Development } \\
\text { and Function, Tissue Development }\end{array}$ & Osteogenic differentiation of nucleus pulposus cells & $1.36 \mathrm{E}-03$ & \\
\hline $\begin{array}{l}\text { Cancer, Gastrointestinal Disease, Organismal Injury and } \\
\text { Abnormalities }\end{array}$ & Stage I colorectal adenocarcinoma & $1.36 \mathrm{E}-03$ & \\
\hline
\end{tabular}

CTNNB1, and SP1, in network 2; Histone H3, MDM2, CCNA2, SOX2, POU2F1, SP1, and ESR1 are the central regulators linked with DE lncRNAs.

\section{Differentially expressed IncRNAs in the Group 3 subgroup} and their functional roles

Comparative analyses of the Group $3 \mathrm{MB}(N=16)$ and normal cerebellum tissue $(N=5)$ datasets with $p<$ 0.05 and fold change $>2$ provided 149 differentially expressed lncRNAs with approved status. Tables 9 and 10 show the fold change in the top 10 upregulated and downregulated lncRNAs. Heatmap of top 10 upregulated and downregulated lncRNAs is shown in Fig. 3a. The complete list of lncRNAs can be seen in Additional file 1 . We found $86 \%$ overlap with lncRNAs in validation datasets [Group $3 N=46$, Control $\mathrm{N}=5$ ] (Additional file 2). We found all the top 10 upregulated and downregulated lncRNAs in the validation dataset, except NEAT1.

Table 9 Top 10 up-regulated IncRNAs in Group 3 of MB

\begin{tabular}{llll}
\hline Gene Symbol & Fold Change & $P$-val & FDR P-val \\
\hline OTX2-AS1 & 80.96 & $1.03 \mathrm{E}-14$ & $1.38 \mathrm{E}-11$ \\
BLACAT1 & 24.59 & $6.32 \mathrm{E}-08$ & $3.32 \mathrm{E}-06$ \\
LINC00348 & 19.06 & 0.0013 & 0.0077 \\
LINC01355 & 9.91 & $1.54 \mathrm{E}-08$ & $1.09 \mathrm{E}-06$ \\
DLEU2 & 8.97 & $2.31 \mathrm{E}-09$ & $2.49 \mathrm{E}-07$ \\
PGM5-AS1 & 7.73 & $4.32 \mathrm{E}-05$ & 0.0005 \\
NEAT1 & 7.27 & 0.0082 & 0.0315 \\
DSCR8 & 6.73 & 0.0104 & 0.0378 \\
PRR34-AS1 & 6.63 & $1.37 \mathrm{E}-06$ & $3.58 \mathrm{E}-05$ \\
MIRLET7BHG & 6.32 & 0.0004 & 0.003 \\
\hline
\end{tabular}

Functional analysis of DE lncRNAs of Group $3 \mathrm{MB}$ using IPA predicted C17orf98, ZNF426, RNF165, FBXO8, CTCF, LAYN, PYGO1, Firre, TSIX and miR150-5pa as most significantly associated upstream regulators, while activation/inactivation of X-chromosome, cell movement, and metastasis are the most important biological functions affected in this subgroup (Tables 11 and 12). Heatmap of 5 upstream regulators is shown in supplementary Fig. 2 (Additional file 3). The two most important non-canonical networks enriched with DE lncRNAs are shown in Fig. $3 \mathrm{~b}$ and c. In network 1; CCND1, EP300, CREBBP, ESR1, CTNNB1, and PRKCD, in network 2; Histone H3, TP53, MYC, XIST, and EZH2 are the central regulators linked with DE lncRNAs.

\section{Differentially expressed IncRNAs in the Group 4 MB and their functional roles}

Comparative analyses of Group $4 \mathrm{MB}(N=39)$ and normal cerebellar tissue $(N=5)$ datasets with $p<0.05$ and

Table 10 Top 10 down-regulated IncRNAs in Group 3 of MB

\begin{tabular}{llll}
\hline Gene Symbol & Fold Change & $P$-val & FDR $P$-val \\
\hline XIST & -315.1 & 0.0066 & 0.0267 \\
MEG3 & -58.01 & 0.0001 & 0.0011 \\
SOX2-OT & -50.3 & $1.15 \mathrm{E}-14$ & $1.44 \mathrm{E}-11$ \\
LINC00844 & -37.6 & $6.71 \mathrm{E}-08$ & $3.47 \mathrm{E}-06$ \\
MIR100HG & -16.61 & $1.16 \mathrm{E}-06$ & $3.15 \mathrm{E}-05$ \\
HCG11 & -12.99 & $1.93 \mathrm{E}-05$ & 0.0003 \\
MIAT & -10.36 & 0.0002 & 0.0016 \\
LINC00461 & -9.38 & 0.002 & 0.0105 \\
LINC00643 & -9.34 & 0.0005 & 0.0036 \\
TRHDE-AS1 & -7.59 & $7.27 \mathrm{E}-09$ & $6.14 \mathrm{E}-07$ \\
\hline
\end{tabular}




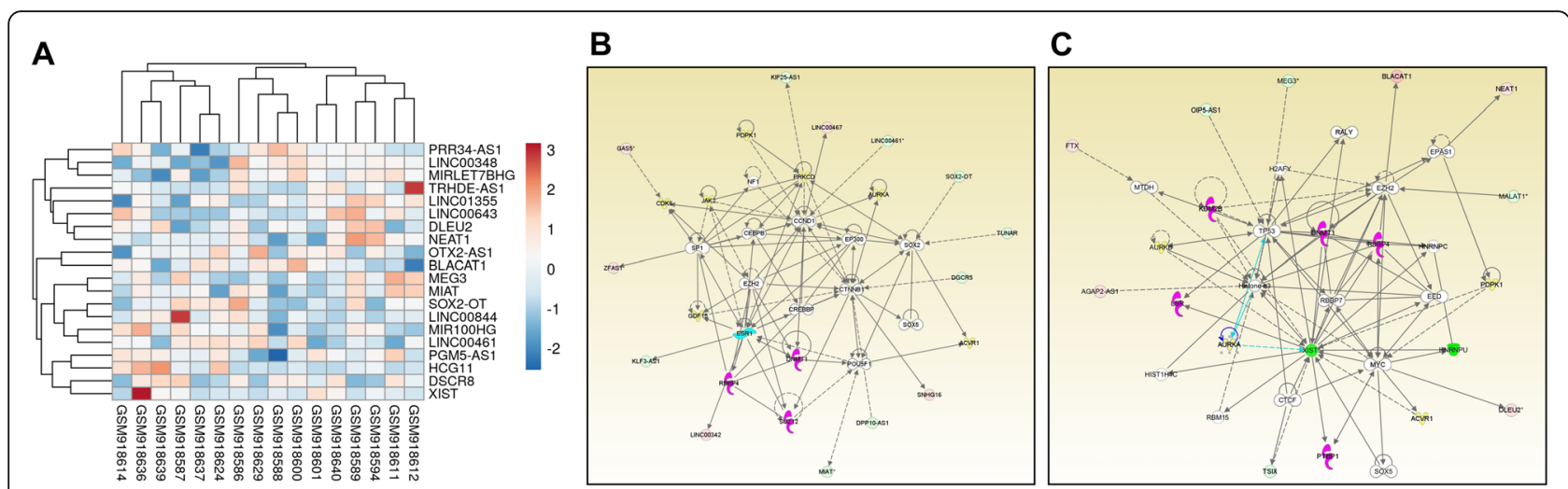

Fig. 3 a: Heatmap of top 10 upregulated and downregulated IncRNAs in Group 3 MB. Expression value of different IncRNAs was clustered using correlation distance method. b: Differentially expressed IncRNAs in a non-canonical biological network in Group 3 MB. The important nodes in this biological network are CCND1, EP300, CREBBP, ESR1, CTNNB1, and PRKCD. c: Differentially expressed IncRNAs in another non-canonical biological network in Group 3 MB. The important nodes in this biological network are Histone H3, TP53, MYC, XIST, and EZH2. Green indicates downregulated and red indicates upregulated IncRNAs

fold change $>2$ provided 150 differentially expressed lncRNAs with approved status. Tables 13 and 14 show the fold change in the top 10 upregulated and downregulated lncRNAs. Heatmap of top 10 upregulated and downregulated lncRNAs is shown in Fig. 4a. The complete list of lncRNAs can be seen in Supplementary file 1 . We found $82 \%$ overlap with lncRNAs in validation datasets [Group 4N=95, Control =5] (Additional file 2). We found all the top 10 upregulated and downregulated lncRNAs in validation datasets.

Functional analysis of DE lncRNAs of Group $4 \mathrm{MB}$ using IPA predicted C17orf98, ZNF426, RNF165, FBXO8, CTCF, LAYN, PYGO1, Firre, TSIX and miR$150-5 \mathrm{pa}$ as most significantly associated upstream regulators, while activation/inactivation of X-chromosomes, cell movement, methylation of DNA and metastasis are the most important biological functions affected in this subgroup (Tables 15 and 16). Heatmap of 5 upstream regulators is shown in supplementary Fig. 2 (Additional file 3). The two important non-canonical networks enriched with DE lncRNAs are shown in Fig. $4 \mathrm{~b}$ and c. In network 1; AR, MYC, XIST, SP1, CCND1, and EZH2, in network 2; Histone H3, SP1, ESR1, MYC, SOX2, POU5F1, CDH1, and CEBPB are the central regulators linked with DE lncRNAs.

\section{Prognostic significance of IncRNAs in different subgroups of $M B$}

We used a publicly available dataset GSE85217 (Cavalli dataset) to understand the prognostic significance of $\mathrm{DE}$ lncRNAs of different MB subgroups. As shown in Fig. 5, high expression of HAND2-AS1 is associated with poor prognosis in WNT MB. Similarly, low expression of MEG3 in SHH, high expression of DLEU2 and DSCR8

Table 11 Top 10 upstream regulators involved in DE IncRNAs in Group 3 MB

\begin{tabular}{llll}
\hline Upstream Regulator & Molecule Type & $P$-val of overlap & Target molecules in dataset \\
\hline C170rf98 & other & $1.11 \mathrm{E}-03$ & XIST \\
ZNF426 & transcription regulator & $1.11 \mathrm{E}-03$ & XIST \\
RNF165 & enzyme & $1.11 \mathrm{E}-03$ & XIST \\
FBXO8 & other & $1.11 \mathrm{E}-03$ & XIST \\
CTCF & transcription regulator & $2.08 \mathrm{E}-03$ & TSIX,XIST \\
LAYN & other & $2.22 \mathrm{E}-03$ & XIST \\
PYGO1 & other & XIST \\
Firre & other & $3.22 \mathrm{E}-03$ & XIST \\
TSIX & other & $3.33 \mathrm{E}-03$ & XIST \\
miR-150-5p (and other miRNAs w/seed CUCCCAA) & mature microRNA & $3.33 \mathrm{E}-03$ & MIAT \\
\hline
\end{tabular}


Table 12 Top 10 disease and function identified by IPA from DE IncRNAs in Group 3 MB

\begin{tabular}{llll}
\hline Categories & Diseases or Functions Annotation & $P$-val & Activation z-score \\
\hline Gene Expression & Inactivation of mouse X chromosome & $5.74 \mathrm{E}-06$ & $5.74 \mathrm{E}-06$ \\
Gene Expression & Activation of mouse X chromosome & $2.36 \mathrm{E}-05$ \\
Cellular Movement & Cell movement of tumor cell lines & $3.60 \mathrm{E}-05$ \\
Cellular Movement & Migration of tumor cell lines & $1.65 \mathrm{E}-04$ \\
Cell Cycle & Arrest in Go phase of tumor cell lines & $6.99 \mathrm{E}-04$ \\
Cellular Movement & Invasion of tumor cell lines & $1.30 \mathrm{E}-03$ \\
Cellular Movement & Cell movement & $1.31 \mathrm{E}-03$ \\
Gene Expression & Imprinting & $1.32 \mathrm{E}-03$ \\
Cancer, Organismal Injury and Abnormalities & Metastasis of tumor cell lines & $1.41 \mathrm{E}-03$ \\
Hereditary Disorder, Organismal Injury and Abnormalities & Familial skewed X inactivation & 0.495 \\
\hline
\end{tabular}

in Group 3 and high expression of DLEU2 and low expression of XIST in Group 4 are associated with poor prognosis in $\mathrm{MB}(p<0.05)$.

\section{Discussion}

LncRNAs are known regulators of gene expression. Disruptions in gene regulatory pathways in cancers dictate the aberrant LncRNAs expression [11-13]. Notably, almost $40 \%$ of lncRNAs are aberrantly expressed in the brain-related disorders including brain tumors. However, lncRNA expression profile in MB is largely unexplored. In this study, we have identified the lncRNA expression profile of pediatric $\mathrm{MB}$ subgroups and associated molecular pathways. The identified key lncRNAs require further functional validation in vitro and in vivo to explore their potential role in MB subgroup-specific manner. Here, we discuss the known cancer-relevant function of the key lncRNAs identified in $\mathrm{MB}$ subgroups.
EMX2OS is the most differentially expressed lncRNA in the WNT subgroup. This IncRNA is known to regulate $E M X$ gene expression in the brain development [32, 33]. OTX2-AS1 (antisense strand of the OTX2 gene) is predominantly involved in eye development [34]. High PGM5-AS1 (antisense strand of the PGM5 gene) expression is associated with development and poor prognosis of colorectal cancer (CRC) [35]. Increased expression of DSCR8 is associated to malignant pathology and poor survival in hepatocellular carcinoma (HCC) patients [36]. LOXL1-AS1 (antisense strand of the LOXL1 gene) is involved in the progression and metastasis of $M B$ by regulating the PI3K-AKT signaling [27]. In addition, it is also known to play roles in the proliferation and survival of prostate cancer (PC) cells via miR-541-3p and cell cycle gene CCND1 [37] as well as aggressive nature of glioblastoma by activating NF-kB pathway [38]. HAND2-AS1 (antisense strand of the HAND2 gene) is overexpressed in esophageal squamous cell carcinoma (ESCC) [39] while it is downregulated in non-small cell

Table 13 Top 10 up-regulated IncRNAs in Group 4 of MB

\begin{tabular}{llll}
\hline Gene Symbol & Fold Change & $P$-val & FDR P-val \\
\hline LINC01419 & 139.78 & 0.0047 & 0.0175 \\
OTX2-AS1 & 60.12 & $9.95 \mathrm{E}-16$ & $2.03 \mathrm{E}-13$ \\
BLACAT1 & 27.67 & $1.13 \mathrm{E}-18$ & $4.59 \mathrm{E}-16$ \\
DLEU2 & 11.58 & $2.25 \mathrm{E}-15$ & $4.16 \mathrm{E}-13$ \\
LINC01355 & 7.09 & $2.23 \mathrm{E}-07$ & $3.85 \mathrm{E}-06$ \\
MIRLET7BHG & 7.01 & $2.03 \mathrm{E}-06$ & $2.55 \mathrm{E}-05$ \\
PRR34-AS1 & 6.82 & $8.84 \mathrm{E}-12$ & $6.11 \mathrm{E}-10$ \\
LINC01000 & 6.29 & $4.10 \mathrm{E}-12$ & $3.13 \mathrm{E}-10$ \\
CKMT2-AS1 & 6.19 & $5.04 \mathrm{E}-11$ & $2.82 \mathrm{E}-09$ \\
MIR99AHG & 5.27 & $9.82 \mathrm{E}-07$ & $1.38 \mathrm{E}-05$ \\
\hline
\end{tabular}


Table 14 Top 10 down-regulated IncRNAs in Group 4 of MB

\begin{tabular}{llll}
\hline Gene Symbol & Fold Change & $P$-val & FDR P-val \\
\hline XIST & -343.06 & 0.0287 & 0.0745 \\
SOX2-OT & -31.6 & $1.90 \mathrm{E}-13$ & $2.06 \mathrm{E}-11$ \\
MALAT1 & -13.08 & $5.80 \mathrm{E}-10$ & $2.34 \mathrm{E}-08$ \\
LINC00643 & -11.64 & $4.39 \mathrm{E}-13$ & $4.32 \mathrm{E}-11$ \\
LINC00844 & -9.89 & $1.26 \mathrm{E}-05$ & 0.0001 \\
LRRC75A-AS1 & -9.53 & $1.52 \mathrm{E}-08$ & $3.87 \mathrm{E}-07$ \\
MIAT & -7.87 & $2.15 \mathrm{E}-10$ & $9.90 \mathrm{E}-09$ \\
PRKAG2-AS1 & -7.8 & $4.29 \mathrm{E}-07$ & $6.75 \mathrm{E}-06$ \\
NR2F1-AS1 & -5.98 & $8.89 \mathrm{E}-11$ & $4.63 \mathrm{E}-09$ \\
PEG3-AS1 & -5.74 & $1.92 \mathrm{E}-08$ & $4.73 \mathrm{E}-07$ \\
\hline
\end{tabular}

lung cancer (NSCLC) cells [40]. TMEM51-AS1 (antisense strand of the TMEM51 gene) is associated with renal cell carcinoma (RCC) [41]. RMST acts as a tumor suppressor in triple-negative breast cancer (TNBC) by inducing apoptosis and inhibiting proliferation/invasion and migration [42]. PART1 promotes gefitinib-resistance in ESCC by regulating the miR-129/Bcl-2 pathway [43] and also associated with PC tumorigenesis [44]. LINC00461 is involved in glioma tumorigenesis via MAPK/ERK and PI3K/AKT signaling pathways [45]. Downregulation of MEG3 is involved in the proliferation and apoptosis of PC cells by regulating miR-9-5p and its target gene QKI-5 [46]. Downregulation of LINC00844 is associated with poor clinical outcomes and suppressed tumor progression/metastasis in PC [47]. SOX2-OT is overexpressed and promotes tumorigenesis by upregulating SOX2 gene and activating PI3K/AKT signaling pathway in cholangiocarcinoma (CCA) [48]. SOX2-OT is also a prognostic biomarker for osteosarcoma (OS) and involved in cell survival and cancer stem cells [49]. TUNAR plays a tumor suppressive role in glioma cells by upregulating miR-200a and inhibiting Rac1 [50]. MALAT1 promotes the chemo-resistance of cervical cancer via BRWD1-PI3K/AKT pathway [51]. MALAT1 is a well-studied lncRNA in several solid and hematological cancers [52].

NEAT1 is overexpressed in most cancer types, except leukemia and myeloma, where it is down-regulated [5355]. DLEU2 exhibits role in the proliferation and survival of laryngeal cancer cells via miR-16-1 [56]. DLEU2 is also significantly overexpressed in gastric cancer and contributes to cell proliferation [57]. TPT1-AS1 (antisense strand of the TPT1 gene) expression is upregulated in cervical cancer and has influence on proliferation and migration
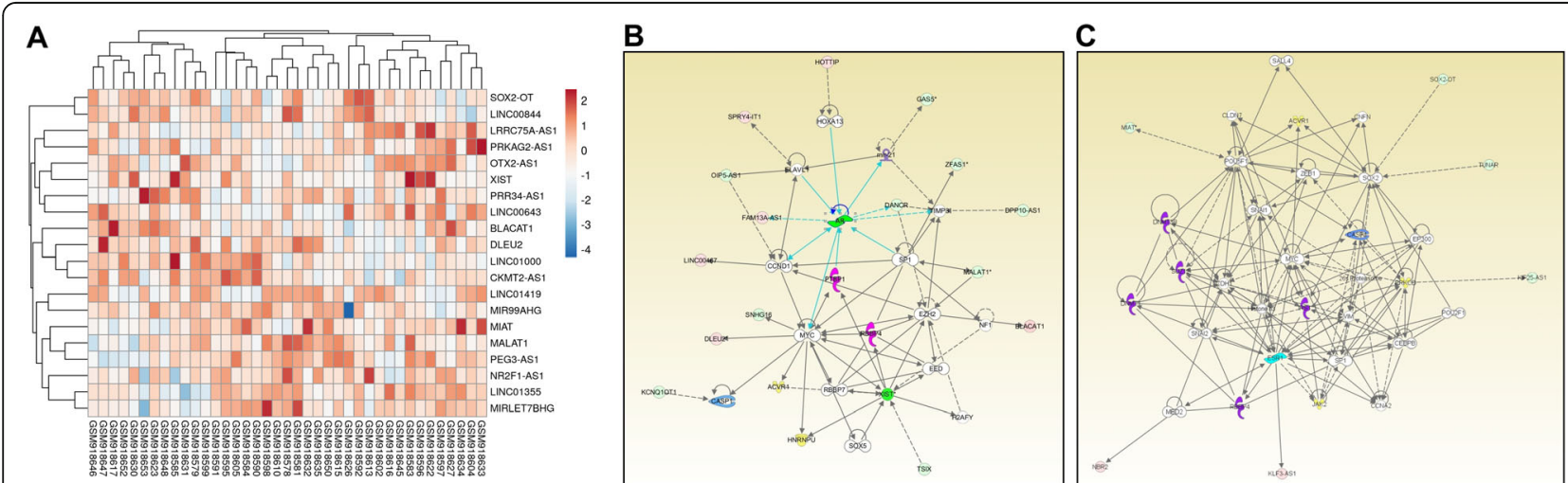

Fig. 4 a: Heatmap of top 10 upregulated and downregulated IncRNAs in Group 4 MB. Expression value of different IncRNAs was clustered using correlation distance method. b: Differentially expressed IncRNAs in a non-canonical biological network in Group 4 MB. The important nodes in this biological network are AR, MYC, XIST, SP1, CCND1, and EZH2. c: Differentially expressed IncRNAs in another non-canonical biological network in Group 4 MB. The important nodes in this biological network are Histone H3, SP1, ESR1, MYC, SOX2, POU5F1, CDH1, and CEBPB. Green indicates downregulated and red indicates upregulated IncRNAs 
Table 15 Top 10 upstream regulators involved in DE IncRNAs in Group 4 MB

\begin{tabular}{llll}
\hline Upstream Regulator & Molecule Type & $P$-val of overlap & Target molecules in dataset \\
\hline C17orf98 & other & $1.34 \mathrm{E}-03$ & XIST \\
ZNF426 & transcription regulator & $1.34 \mathrm{E}-03$ & XIST \\
RNF165 & enzyme & $1.34 \mathrm{E}-03$ & XIST \\
FBXO8 & other & $1.34 \mathrm{E}-03$ & XIST \\
LAYN & other & $2.68 \mathrm{E}-03$ & XIST \\
PYGO1 & other & $2.68 \mathrm{E}-03$ & XIST \\
CTCF & transcription regulator & $3.03 \mathrm{E}-03$ & TSIX,XIST \\
Firre & other & $4.02 \mathrm{E}-03$ & XIST \\
TSIX & other & $4.02 \mathrm{E}-03$ & XIST \\
miR-150-5p (and other miRNAs w/seed CUCCCAA) & mature microRNA & $4.02 \mathrm{E}-03$ & MIAT
\end{tabular}

[58]. HCG11 is significantly overexpressed in hepatocellular carcinoma (HCC) and genetic-silencing of HCG11 in HCC cells leads to decreased proliferation [59]. HCG11 expression is downregulated in $\mathrm{PC}$ and associated with poor prognosis of patients [60]. CCEPR contributes significantly in promoting cell proliferation and inhibiting apoptosis in bladder cancer [61].

BLACAT1 is overexpressed in chemo-resistant NSCLC and induces autophagy by regulating miR-17 and ATG7 pathway [62]. It also triggers proliferation/ survival by regulating WNT signaling in cervical cancer [63].

XIST is elevated in bladder cancer and inhibits p53 function via binding to TET1 [64]. XIST also binds to miR-34a and elicits proliferation and tumor development in thyroid cancer [65]. XIST is an important regulator of progression and oxaliplatin-resistance in malignant melanoma [66]. MIR100HG is known to be involved in cetuximab-resistance in CRC via the $\beta$-catenin cellular pathway [67]. In addition, elevated expression of MIR100HG is correlated with poor prognosis of osteosarcoma [68]. MIAT is overexpressed in clear cell renal cell carcinoma (CCRCC) and associated with poor prognosis [69]. MIAT associates with miR-133 and contributes a role in the progression pancreatic cancer development [70]. MIAT also plays a key role in CRC tumorigenesis via miR-132/Derlin-1 axis [71]. NR2F1AS1 (antisense strand of the NR2F1 gene) promotes chemotherapy-resistance in $\mathrm{HCC}$ by regulating miR363-ABCC1 drug-transporter pathway [72].

\section{Conclusions}

We propose that the majority of DE lncRNAs in MB might have oncogenic properties as seen in other cancers (Supplementary Table S1 in Additional file 3) [7382]. We found approximately $25 \%$ of these DE lncRNAs in $\mathrm{MB}$ are tumor suppressive. Also, each MB subgroup has unique and common lncRNAs in their expression

Table 16 Top 10 disease and function identified by IPA from DE IncRNAs in Group 4 MB

\begin{tabular}{llll}
\hline Categories & Diseases or Functions Annotation & $P$-val & Activation z-score \\
\hline Cellular Movement & Cell movement of tumor cell lines & $4.56 \mathrm{E}-06$ & -0.938 \\
Gene Expression & Inactivation of mouse X chromosome & $6.13 \mathrm{E}-06$ \\
Gene Expression & Activation of mouse X chromosome & $6.13 \mathrm{E}-06$ \\
Cellular Movement & Migration of tumor cell lines & $6.36 \mathrm{E}-06$ \\
Gene Expression & Imprinting & $2.27 \mathrm{E}-05$ \\
Cell Death and Survival & Apoptosis of kidney cancer cell lines & $3.30 \mathrm{E}-05$ \\
Cancer, Organismal Injury and Abnormalities & Metastasis of tumor cell lines & $1.28 \mathrm{E}-04$ \\
Cellular Movement & Invasion of tumor cell lines & $1.36 \mathrm{E}-04$ \\
Cellular Development, Cellular Growth and Proliferation & Proliferation of kidney cancer cell lines & $1.68 \mathrm{E}-04$ \\
DNA Replication, Recombination, and Repair, Gene Expression & Methylation of DNA & $1.82 \mathrm{E}-04$ \\
Cell Death and Survival & Cell death of eye cell lines & $3.08 \mathrm{E}-04$ \\
\hline
\end{tabular}


A

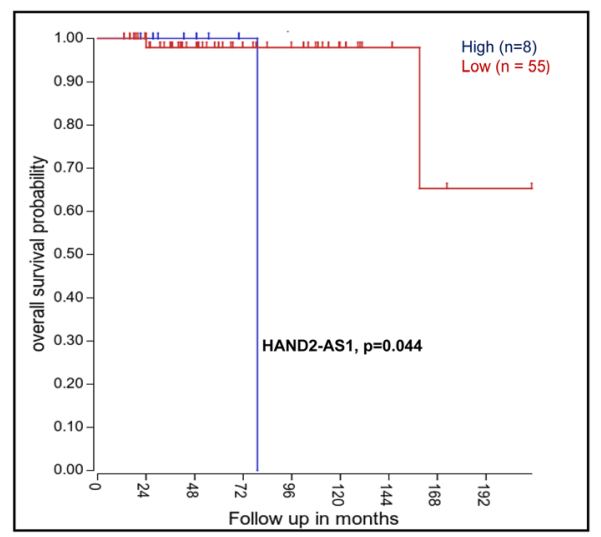

C

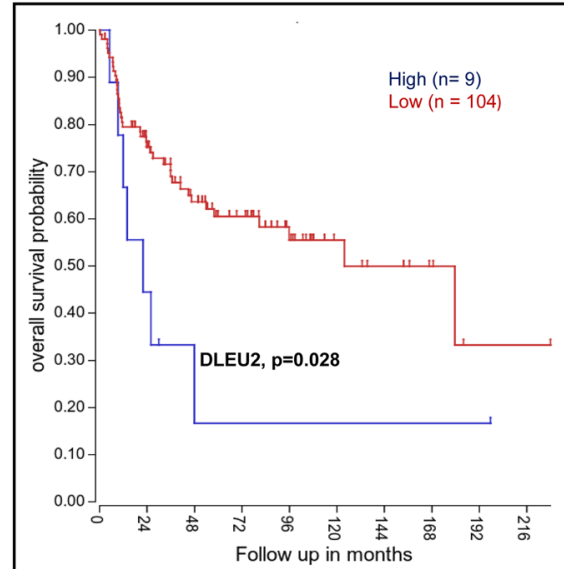

D

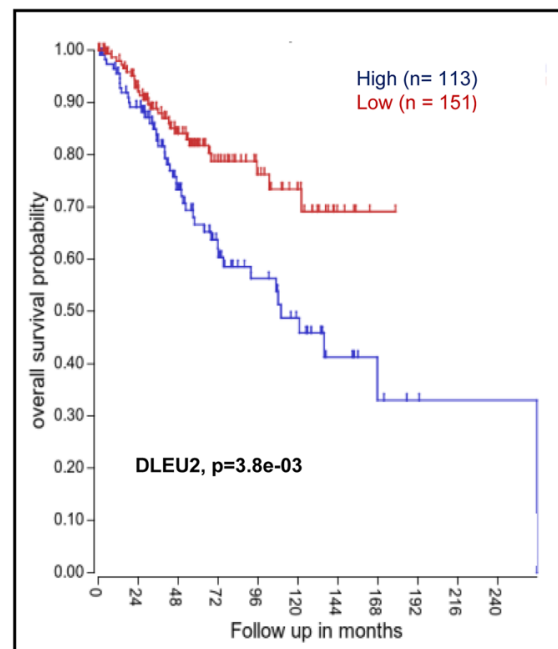

B

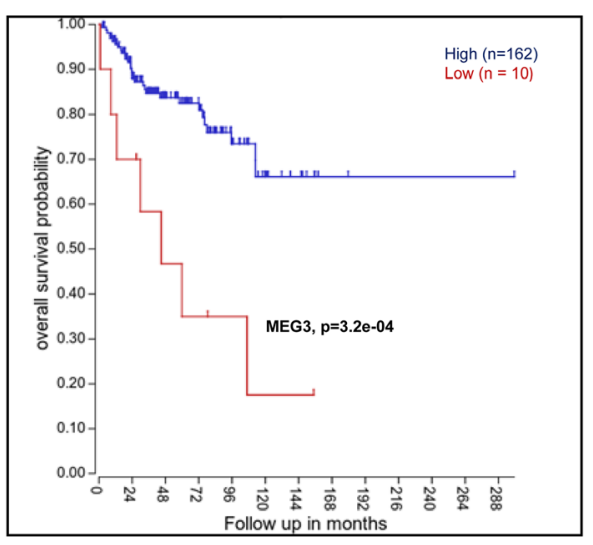

Follow up in months 8 \%
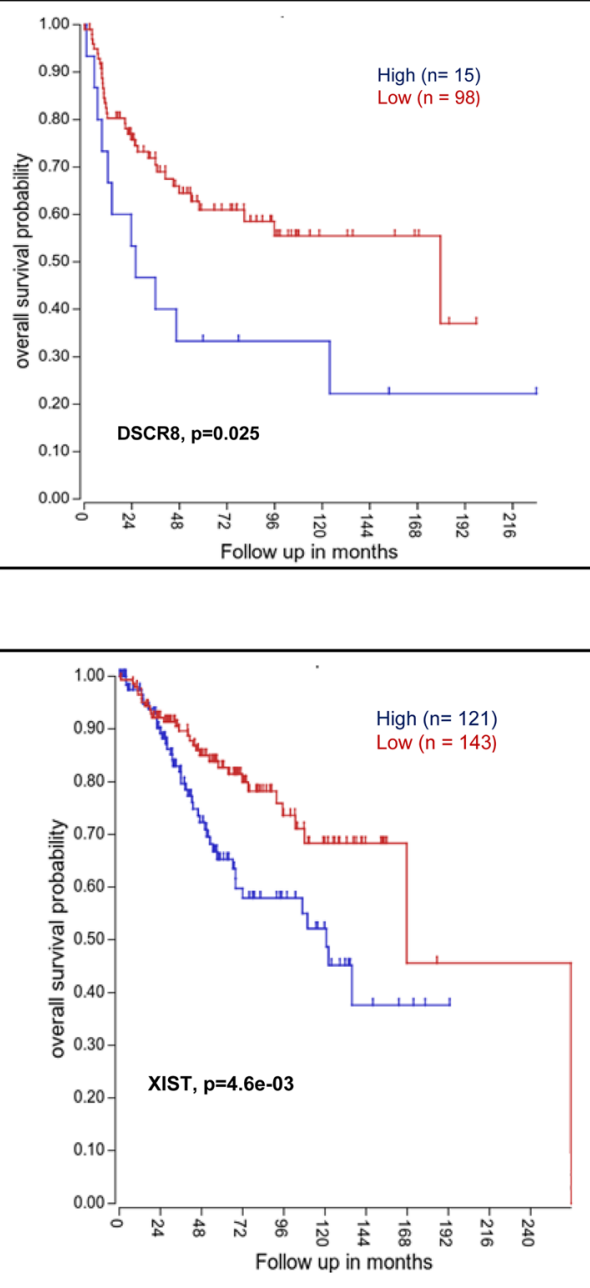

Fig. 5 Kaplan Meier survival curves of different IncRNAs expressed in different subgroups of MB (Cavalli dataset) obtained using scan cut-off method on hgserver (https://hgserver1.amc.nl). a: High expression of HAND2-AS1 is associated with poor prognosis in WNT MB. b: Low expression of MEG3 is associated with poor prognosis in SHH MB. c: High expression of DLEU2 and DSCR8 are associated with poor prognosis in Group 3 MB. d: High expression of DLEU2 and low expression of XIST in Group 4 MB are associated with poor prognosis $(p<0.05)$ 


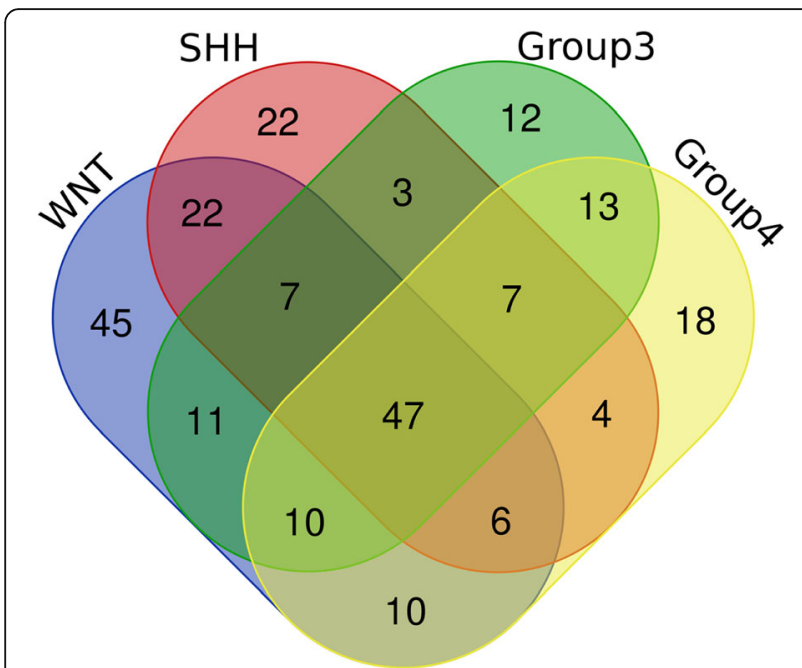

Fig. 6 Venn diagram shows unique and overlapping IncRNAs profile in different MB subgroups. A complete list of unique IncRNAs in each subgroup can be viewed in supplementary file (highlighted in purple in Additional file 1)

profile (Fig. 6). We performed a unique lncRNAs analysis in both original datasets and validation datasets (Additional files 1 and 2). Unique lncRNAs can be validated for differential diagnosis and prognosis of MB subgroups. Common lncRNAs and associated molecules in pathways can be important therapeutic targets. We identified important lncRNAs DELU2, CASC15, LINC01355 and GAS5 are present in each subgroup and can be further explored for functional analyses in different $\mathrm{MB}$ subgroups. We also found SOX2, Protein kinase $\mathrm{C}$ delta (PRKCD), and EZH2 associated with functional networks of each subgroup and could be important drug targets. We also identified the prognostic significance of lncRNAs in different subgroups of MB.

\section{Supplementary information}

Supplementary information accompanies this paper at https://doi.org/10. 1186/s12920-020-00744-7.

\section{Additional file 1. \\ Additional file 2. \\ Additional file 3.}

\section{Abbreviations}

MB: Medulloblastoma; LncRNAs: Long-non-coding RNAs; GEO: Gene Expression Omnibus; DE: Differentially expressed; mRNA: Messenger ribonucleic acid; DNA: Deoxyribonucleic acid; IPA: Ingenuity pathway analysis; ANOVA: Analysis of variance

\section{Acknowledgements}

The authors wish to acknowledge the support of Bioinformatics Core Facility for providing access to IPA for functional analysis of datasets. The authors thank the State of Nebraska for their financial support of the UNMC/CHRI/ Children's Hospital Pediatric Cancer Research Program.

\section{Authors' contributions}

VK and NKC conceived and designed the study. VK, MS and NKC analyzed and interpreted the data. DC, JGS and SSJ critically interpreted the data. VK and NKC wrote the manuscript. All authors read and approved the final version of the manuscript.

\section{Funding}

This work was supported by the State of Nebraska through the Pediatric Cancer Research Grant Funds (LB905) awarded to D. W. Coulter, MD. This funding had no role in the study design, data collection and analysis, interpretation of the data, decision to publish, or writing the manuscript.

\section{Availability of data and materials}

We used publicly available GEO datasets (https://www.ncbi.nlm.nih.gov/geo/) GSE37418, GSM1094863, GSM1094864, GSM1094865, GSM1094866, GSM1094867, GSE124814, and GSE85217 for our analyses. The gene expression data GSE85217 (Cavalli dataset) was used for survival analyses in the R2-Genomics Analysis and Visualization Platform (https://hgserver1.amc. $\mathrm{nl} /$ cgi-bin/r2/main.cgi).

Ethics approval and consent to participate

Not applicable.

\section{Consent for publication}

Not applicable.

\section{Competing interests}

The authors declare that they have no competing interest.

\section{Author details}

${ }^{1}$ Child Health Research Institute, University of Nebraska Medical Center, Omaha, NE 69198, USA. ²Department of Genetics, Cell Biology and Anatomy, University of Nebraska Medical Center, Omaha, NE 69198, USA. ${ }^{3}$ Department of Pediatrics, Hematology and Oncology Division, University of Nebraska Medical Center, Omaha, NE 986395, USA. ${ }^{4}$ Nebraska Medical Center, Omaha, NE, USA.

Received: 26 March 2020 Accepted: 19 June 2020

Published online: 26 June 2020

\section{References}

1. Cho YJ, Tsherniak A, Tamayo P, Santagata S, Ligon A, Greulich H, et al. Integrative genomic analysis of medulloblastoma identifies a molecular subgroup that drives poor clinical outcome. J Clin Oncol. 2011;29:1424-30.

2. Kijima N, Kanemura Y. Molecular Classification of Medulloblastoma. Neurol Med Chir (Tokyo). 2016;56:687-97.

3. Spiegler BJ, Bouffet E, Greenberg ML, Rutka JT, Mabbott DJ. Change in neurocognitive functioning after treatment with cranial radiation in childhood. J Clin Oncol. 2004;22:706-13.

4. Zeltzer LK, Recklitis C, Buchbinder D, Zebrack B, Casillas J, Tsao JC, et al. Psychological status in childhood cancer survivors: a report from the childhood Cancer survivor study. J Clin Oncol. 2009;27:2396-404.

5. Northcott PA, Korshunov A, Witt H, Hielscher T, Eberhart CG, Mack S, et al. Medulloblastoma comprises four distinct molecular variants. J Clin Oncol. 2011;29:1408-14.

6. Northcott PA, Shih DJ, Peacock J, Garzia L, Morrissy AS, Zichner T, et al. Subgroup-specific structural variation across 1,000 medulloblastoma genomes. Nature. 2012;488:49-56.

7. Jones DT, Jager N, Kool M, Zichner T, Hutter B, Sultan M, et al. Dissecting the genomic complexity underlying medulloblastoma. Nature. 2012;488: 100-5.

8. Robinson G, Parker M, Kranenburg TA, Lu C, Chen X, Ding L, et al. Novel mutations target distinct subgroups of medulloblastoma. Nature. 2012;488: 43-8.

9. Kool M, Korshunov A, Remke M, Jones DT, Schlanstein M, Northcott PA, et al. Molecular subgroups of medulloblastoma: an international metaanalysis of transcriptome, genetic aberrations, and clinical data of WNT, $\mathrm{SHH}$, group 3, and group 4 medulloblastomas. Acta Neuropathol. 2012;123: 473-84. 
10. Taylor MD, Northcott PA, Korshunov A, Remke M, Cho YJ, Clifford SC, et al. Molecular subgroups of medulloblastoma: the current consensus. Acta Neuropathol. 2012;123:465-72.

11. Harrow J, Frankish A, Gonzalez JM, Tapanari E, Diekhans M, Kokocinski F, et al. GENCODE: the reference human genome annotation for the ENCODE project. Genome Res. 2012;22:1760-74.

12. Fatica A, Bozzoni I. Long non-coding RNAs: new players in cell differentiation and development. Nat Rev Genet. 2014;15:7-21.

13. Shen XH, Qi P, Du X. Long non-coding RNAs in cancer invasion and metastasis. Mod Pathol. 2015;28:4-13.

14. Huarte M, Rinn JL. Large non-coding RNAs: missing links in cancer? Hum Mol Genet. 2010;19:R152-61.

15. Grossi E, Sanchez Y, Huarte M. Expanding the p53 regulatory network: LncRNAs take up the challenge. Biochim Biophys Acta. 1859;2016:200-8.

16. Qi P, Zhou XY, Du X. Circulating long non-coding RNAs in cancer: current status and future perspectives. Mol Cancer. 2016;15:39.

17. Do H, Kim W. Roles of oncogenic Long non-coding RNAs in Cancer development. Genomics Inform. 2018;16:e18.

18. de Oliveira JC, Oliveira LC, Mathias C, Pedroso GA, Lemos DS, Salviano-Silva A, et al. Long non-coding RNAs in cancer: Another layer of complexity. J Gene Med. 2018:e3065.

19. Tinzl $M$, Marberger $M$, Horvath $S$, Chypre C. DD3PCA3 RNA analysis in urine--a new perspective for detecting prostate cancer. Eur Urol. 2004;46: 182-6.

20. Isin M, Ozgur E, Cetin G, Erten N, Aktan M, Gezer U, et al. Investigation of circulating IncRNAs in B-cell neoplasms. Clin Chim Acta. 2014;431:255-9.

21. Roberts TC, Morris KV, Wood MJ. The role of long non-coding RNAs in neurodevelopment, brain function and neurological disease. Philos Trans R Soc Lond Ser B Biol Sci. 2014;369.

22. Pavlaki I, Alammari F, Sun B, Clark N, Sirey T, Lee S, et al. The long noncoding RNA Paupar promotes KAP1-dependent chromatin changes and regulates olfactory bulb neurogenesis. EMBO J. 2018;37.

23. Wu P, Zuo X, Deng H, Liu X, Liu L, Ji A. Roles of long noncoding RNAs in brain development, functional diversification and neurodegenerative diseases. Brain Res Bull. 2013;97:69-80

24. Cho KO, Hsieh J. The IncRNA Pnky in the brain. Cell Stem Cell. 2015;16:344-5.

25. Ramos AD, Andersen RE, Liu SJ, Nowakowski TJ, Hong SJ, Gertz C, et al. The long noncoding RNA Pnky regulates neuronal differentiation of embryonic and postnatal neural stem cells. Cell Stem Cell. 2015;16:439-47.

26. Briggs JA, Wolvetang EJ, Mattick JS, Rinn JL, Barry G. Mechanisms of Long non-coding RNAs in mammalian nervous system development, plasticity, disease, and evolution. Neuron. 2015;88:861-77.

27. Gao R, Zhang R, Zhang C, Liang Y, Tang W. LncRNA LOXL1-AS1 Promotes the Proliferation and Metastasis of Medulloblastoma by Activating the PI3K AKT Pathway. Anal Cell Pathol (Amst). 2018;2018:9275685.

28. Gao R, Zhang R, Zhang C, Zhao L, Zhang Y. Long noncoding RNA CCAT1 promotes cell proliferation and metastasis in human medulloblastoma via MAPK pathway. Tumori. 2018;104:43-50

29. Zhang $H$, Wang $X$, Chen X. Potential role of Long non-coding RNA ANRIL in pediatric Medulloblastoma through promotion on proliferation and migration by targeting miR-323. J Cell Biochem. 2017;118:4735-44.

30. Laneve P, Po A, Favia A, Legnini I, Alfano V, Rea J, et al. The long noncoding RNA linc-NeD125 controls the expression of medulloblastoma driver genes by microRNA sponge activity. Oncotarget. 2017;8:31003-15.

31. Song $H$, Han LM, Gao Q, Sun Y. Long non-coding RNA CRNDE promotes tumor growth in medulloblastoma. Eur Rev Med Pharmacol Sci. 2016;20: 2588-97.

32. Noonan FC, Goodfellow PJ, Staloch LJ, Mutch DG, Simon TC. Antisense transcripts at the EMX2 locus in human and mouse. Genomics. 2003;81:58-66.

33. Cecchi C, Boncinelli E. Emx homeogenes and mouse brain development. Trends Neurosci. 2000;23:347-52.

34. Alfano G, Vitiello C, Caccioppoli C, Caramico T, Carola A, Szego MJ, et al. Natural antisense transcripts associated with genes involved in eye development. Hum Mol Genet. 2005;14:913-23.

35. Zhu H, Yu J, Zhu H, Guo Y, Feng S. Identification of key IncRNAs in colorectal cancer progression based on associated protein-protein interaction analysis. World J Surg Oncol. 2017;15:153.

36. Wang $Y$, Sun $L$, Wang L, Liu Z, Li Q, Yao B, et al. Long non-coding RNA DSCR8 acts as a molecular sponge for miR-485-5p to activate Wnt/beta-851.

37. Long B, Li N, Xu XX, Li XX, Xu XJ, Liu JY, et al. Long noncoding RNA LOXL1AS1 regulates prostate cancer cell proliferation and cell cycle progression through miR-541-3p and CCND1. Biochem Biophys Res Commun. 2018;505: $561-8$.

38. Wang H, Li L, Yin L. Silencing LncRNA LOXL1-AS1 attenuates mesenchymal characteristics of glioblastoma via NF-kappaB pathway. Biochem Biophys Res Commun. 2018;500:518-24

39. Yan Y, Li S, Wang S, Rubegni P, Tognetti L, Zhang J, et al. Long noncoding RNA HAND2-AS1 inhibits cancer cell proliferation, migration, and invasion in esophagus squamous cell carcinoma by regulating microRNA-21. J Cell Biochem. 2019;120:9564-71.

40. Miao F, Chen J, Shi M, Song Y, Chen Z, Pang L. LncRNA HAND2-AS1 inhibits non-small cell lung cancer migration, invasion and maintains cell stemness through the interactions with TGF-beta1. Biosci Rep. 2019;39:BSR20181525.

41. He HT, Xu M, Kuang Y, Han XY, Wang MQ, Yang Q. Biomarker and competing endogenous RNA potential of tumor-specific long noncoding RNA in chromophobe renal cell carcinoma. Onco Targets Ther. 2016;9:6399-406.

42. Wang L, Liu D, Wu X, Zeng Y, Li L, Hou Y, et al. Long non-coding RNA (LnCRNA) RMST in triple-negative breast cancer (TNBC): expression analysis and biological roles research. J Cell Physiol. 2018;233:6603-12.

43. Kang M, Ren M, Li Y, Fu Y, Deng M, Li C. Exosome-mediated transfer of IncRNA PART1 induces gefitinib resistance in esophageal squamous cell carcinoma via functioning as a competing endogenous RNA. J Exp Clin Cancer Res. 2018;37:171

44. Sun M, Geng D, Li S, Chen Z, Zhao W. LnCRNA PART1 modulates toll-like receptor pathways to influence cell proliferation and apoptosis in prostate cancer cells. Biol Chem. 2018;399:387-95.

45. Yang Y, Ren M, Song C, Li D, Soomro SH, Xiong Y, et al. LINC00461, a long non-coding RNA, is important for the proliferation and migration of glioma cells. Oncotarget. 2017;8:84123-39.

46. Wu M, Huang $Y$, Chen T, Wang W, Yang $S$, Ye Z, et al. LncRNA MEG3 inhibits the progression of prostate cancer by modulating miR-9-5p/QKI-5 axis. J Cell Mol Med. 2019;23:29-38.

47. Lingadahalli $\mathrm{S}$, Jadhao S, Sung YY, Chen M, Hu L, Chen $X$, et al. Novel InCRNA LINC00844 regulates prostate Cancer cell migration and invasion through AR signaling. Mol Cancer Res. 2018;16:1865-78.

48. Wei CX, Wong H, Xu F, Liu Z, Ran L, Jiang RD. IRF4-induced upregulation of IncRNA SOX2-OT promotes cell proliferation and metastasis in cholangiocarcinoma by regulating SOX2 and PI3K/AKT signaling. Eur Rev Med Pharmacol Sci. 2018;22:8169-78.

49. Wang Z, Tan M, Chen G, Li Z, Lu X. LncRNA SOX2-OT is a novel prognostic biomarker for osteosarcoma patients and regulates osteosarcoma cells proliferation and motility through modulating SOX2. IUBMB Life. 2017;69: 867-76.

50. Dai J, Ma J, Yu B, Zhu Z, Hu Y. Long noncoding RNA TUNAR represses growth, migration, and invasion of human Glioma cells through regulating miR-200a and Rac1. Oncol Res. 2018;27:107-15.

51. Wang N, Hou MS, Zhan Y, Shen XB, Xue HY. MALAT1 promotes cisplatin resistance in cervical cancer by activating the PI3K/AKT pathway. Eur Rev Med Pharmacol Sci. 2018;22:7653-9.

52. Li ZX, Zhu QN, Zhang HB, Hu Y, Wang G, Zhu YS. MALAT1: a potential biomarker in cancer. Cancer Manag Res. 2018;10:6757-68.

53. Liu Z, Wu K, Wu J, Tian D, Chen Y, Yang Z, et al. NEAT1 is a potential prognostic biomarker for patients with nasopharyngeal carcinoma. J Cell Biochem. 2019:120:9831-8.

54. Ghaforui-Fard S, Taheri M. Nuclear enriched abundant transcript 1 (NEAT1): a long non-coding RNA with diverse functions in tumorigenesis. Biomed Pharmacother. 2018;111:51-9.

55. Klec C, Prinz F, Pichler M. Involvement of the long noncoding RNA NEAT1 in carcinogenesis. Mol Oncol. 2019;13:46-60.

56. Xie ZZ, Xiao ZC, Song YX, Li W, Tan GL. Long non-coding RNA Dleu2 affects proliferation, migration and invasion ability of laryngeal carcinoma cells through triggering miR-16-1 pathway. Eur Rev Med Pharmacol Sci. 2018;22: 1963-70.

57. Liu H, Zhang Z, Wu N, Guo H, Zhang H, Fan D, et al. Integrative Analysis of Dysregulated IncRNA-Associated ceRNA Network Reveals Functional IncRNAs in Gastric Cancer. Genes (Basel). 2018:9.

58. Jiang $H$, Huang $G$, Zhao $N$, Zhang $T$, Jiang $M$, He $Y$, et al. Long non-coding RNA TPT1-AS1 promotes cell growth and metastasis in cervical cancer via acting AS a sponge for miR-324-5p. J Exp Clin Cancer Res. 2018:37:169.

59. Xu Y, Zheng Y, Liu H, Li T. Modulation of IGF2BP1 by long non-coding RNA HCG11 suppresses apoptosis of hepatocellular carcinoma cells via MAPK signaling transduction. Int J Oncol. 2017;51:791-800. 
60. Zhang Y, Zhang P, Wan X, Su X, Kong Z, Zhai Q, et al. Downregulation of long non-coding RNA HCG11 predicts a poor prognosis in prostate cancer. Biomed Pharmacother. 2016;83:936-41.

61. Zhan Y, Li Y, Guan B, Chen X, Chen Z, He A, et al. Increased expression of long non-coding RNA CCEPR is associated with poor prognosis and promotes tumorigenesis in urothelial bladder carcinoma. Oncotarget. 2017; 8:44326-34.

62. Huang FX, Chen HJ, Zheng FX, Gao ZY, Sun PF, Peng Q, et al. LncRNA BLACAT1 is involved in chemoresistance of nonsmall cell lung cancer cells by regulating autophagy. Int J Oncol. 2019;54:339-47.

63. Wang $\mathrm{CH}$, Li YH, Tian HL, Bao XX, Wang ZM. Long non-coding RNA BLACAT1 promotes cell proliferation, migration and invasion in cervical cancer through activation of Wnt/beta-catenin signaling pathway. Eur Rev Med Pharmacol Sci. 2018;22:3002-9.

64. Hu B, Shi G, Li Q, Li W, Zhou H. Long noncoding RNA XIST participates in bladder cancer by downregulating p53 via binding to TET1. J Cell Biochem. 2019;120:6330-8.

65. Liu H, Deng H, Zhao Y, Li C, Liang Y. LncRNA XIST/miR-34a axis modulates the cell proliferation and tumor growth of thyroid cancer through METPI3K-AKT signaling. J Exp Clin Cancer Res. 2018;37:279.

66. Pan $B$, Lin $X$, Zhang L, Hong W, Zhang Y. Long noncoding RNA X-inactive specific transcript promotes malignant melanoma progression and oxaliplatin resistance. Melanoma Res. 2019;29:254-62

67. Lu Y, Zhao X, Liu Q, Li C, Graves-Deal R, Cao Z, et al. IncRNA MIR100HGderived miR-100 and miR-125b mediate cetuximab resistance via Wnt/betacatenin signaling. Nat Med. 2017;23:1331-41.

68. Su X, Teng J, Jin G, Li J, Zhao Z, Cao X, et al. ELK1-induced upregulation of long non-coding RNA MIR100HG predicts poor prognosis and promotes the progression of osteosarcoma by epigenetically silencing LATS1 and LATS2. Biomed Pharmacother. 2019;109:788-97.

69. Qu Y, Xiao H, Xiao W, Xiong Z, Hu W, Gao Y, et al. Upregulation of MIAT regulates LOXL2 expression by competitively binding MiR-29c in clear cell renal cell carcinoma. Cell Physiol Biochem. 2018;48:1075-87.

70. Li TF, Liu J, Fu SJ. The interaction of long non-coding RNA MIAT and miR133 play a role in the proliferation and metastasis of pancreatic carcinoma. Biomed Pharmacother. 2018;104:145-50.

71. Liu Z, Wang H, Cai H, Hong Y, Li Y, Su D, et al. Long non-coding RNA MIAT promotes growth and metastasis of colorectal cancer cells through regulation of miR-132/Derlin-1 pathway. Cancer Cell Int. 2018;18:59.

72. Huang $H$, Chen J, Ding CM, Jin X, Jia ZM, Peng J. LncRNA NR2F1-AS1 regulates hepatocellular carcinoma oxaliplatin resistance by targeting ABCC1 via miR-363. J Cell Mol Med. 2018;22:3238-45.

73. Duan M, Fang M, Wang C, Wang H, Li M. LncRNA EMX2OS induces proliferation, invasion and sphere formation of ovarian Cancer cells via regulating the miR-654-3p/AKT3/PD-L1 Axis. Cancer Manag Res. 2020;12: 2141-54.

74. Yan SP, Chu DX, Qiu HF, Xie Y, Wang CF, Zhang JY, et al. LncRNA LINC01305 silencing inhibits cell epithelial-mesenchymal transition in cervical cancer by inhibiting TNXB-mediated PI3K/Akt signalling pathway. J Cell Mol Med. 2019;23:2656-66.

75. Hsu CM, Lin PM, Lin HC, Lai CC, Yang CH, Lin SF, et al. Altered expression of imprinted genes in squamous cell carcinoma of the head and neck. Anticancer Res. 2016;36:2251-8.

76. Ye M, Ma J, Liu B, Liu X, Ma D, Dong K. Linc01105 acts as an oncogene in the development of neuroblastoma. Oncol Rep. 2019. https://doi.org/10. 3892/or.2019.7257.

77. Ai B, Kong X, Wang X, Zhang K, Yang X, Zhai J, et al. LINC01355 suppresses breast cancer growth through $\mathrm{FOXO3-mediated} \mathrm{transcriptional} \mathrm{repression}$ of CCND1. Cell Death Dis. 2019;10:502.

78. Liu HY, Lu SR, Guo ZH, Zhang ZS, Ye X, Du Q, et al. IncRNA SLC16A1-AS1 as a novel prognostic biomarker in non-small cell lung cancer. J Investig Med. 2020;68:52-9.

79. Zhuan B, Lu Y, Chen Q, Zhao X, Li P, Yuan Q, et al. Overexpression of the long noncoding RNA TRHDE-AS1 inhibits the progression of lung cancer via the miRNA-103/KLF4 axis. J Cell Biochem. 2019;120:17616-24.

80. Wang LL, Zhang L, Cui XF. Downregulation of long noncoding RNA LINC01419 inhibits cell migration, invasion, and tumor growth and promotes autophagy via inactivation of the PI3K/Akt1/mTOR pathway in gastric cancer. Ther Adv Med Oncol. 2019;11:1758835919874651.
81. Emmrich S, Streltsov A, Schmidt F, Thangapandi VR, Reinhardt D, Klusmann $\mathrm{JH}$. LincRNAs MONC and MIR100HG act as oncogenes in acute megakaryoblastic leukemia. Mol Cancer. 2014;13:171.

82. Chen J, Lan J, Ye Z, Duan S, Hu Y, Zou Y, et al. Long noncoding RNA LRRC75A-AS1 inhibits cell proliferation and migration in colorectal carcinoma. Exp Biol Med (Maywood). 2019;244:1137-43.

\section{Publisher's Note}

Springer Nature remains neutral with regard to jurisdictional claims in published maps and institutional affiliations.
Ready to submit your research? Choose BMC and benefit from:

- fast, convenient online submission

- thorough peer review by experienced researchers in your field

- rapid publication on acceptance

- support for research data, including large and complex data types

- gold Open Access which fosters wider collaboration and increased citations

- maximum visibility for your research: over $100 \mathrm{M}$ website views per year

At BMC, research is always in progress.

Learn more biomedcentral.com/submissions 